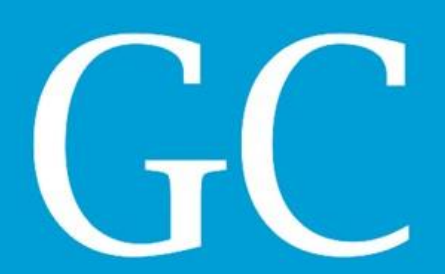

ISSN 2318-8472

v. 06, n. 43,2018

Revista Nacional de

Gerenciamento de Cidades

National Journal of Cities Management

\title{
Planejamento Urbano Saudável: políticas públicas para promoção de Cidades Saudáveis na Itália
}

Healthy Urban Planning: public policies to promote Healthy Cities in Italy

Planificación Urbana Sana: políticas públicas para la promoción de ciudades sanas saludables en Italia

Douglas Gallo

Professor Mestre, IFSP, Brasil Doutorando em Urbanismo, PROURB/FAU/UFRJ, Brasil douglas.luciano@yahoo.com.br

Fabio Silva Santos

Historiador, Brasil Mestre em Relações Internacionais, Universite D’Aux-Marselle-I, França cidades.vivas@gmail.com

Eliane Ribeiro de Almeida da Silva Bessa

Professora Doutora, PROURB/FAU/UFRJ, Brasil elianesilbessa@gmail.com 


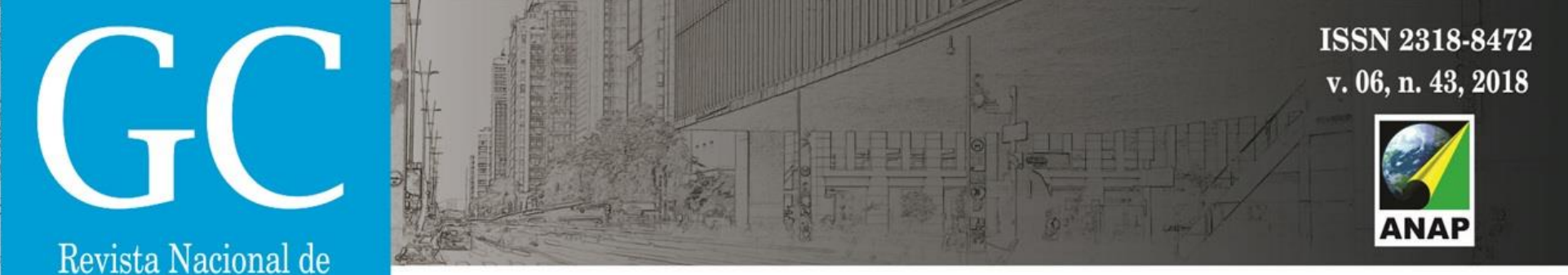

Gerenciamento de Cidades

\section{INTRODUÇÃO}

O presente artigo foi desenvolvido durante o estágio de doutorado sanduíche na Itália, junto ao Dipartimento di Scienze per la Qualità della Vita, da Università di Bologna ${ }^{1}$. Faz parte da pesquisa de doutoramento sobre "Qualidade de Vida Urbana: políticas públicas de promoção da saúde no espaço urbano". O objetivo foi investigar e discutir as relações entre o planejamento urbano e a saúde, especialmente sob a ótica dos programas mundiais da Organização Mundial da Saúde (OMS): Healthy Cities e Healthy Urban Planning ${ }^{2}$. Partindo da experiência italiana procurou-se construir uma reflexão sobre a integralidade das ações de planejamento urbano para promover mais qualidade de vida nas cidades contemporâneas.

No decorrer do século XX houve grande avanço para o bem-estar social, especialmente devido à evolução técnico-científica da modernidade, porém com grande exploração dos recursos naturais planetários, gerando degradação ambiental, exaurimento de recursos e insegurança generalizada. A intervenção do Estado mediante políticas de bem-estar (welfare) incidiu sobre as condições de vida das massas, especialmente em termos de certezas e garantias existenciais (AGUSTONI, 2015). A sociedade contemporânea tornou-se predominante urbana (LEFEBVRE, 1999, 2001), gerando questões importantes para a vida humana e consequentemente para o planejamento (CASTELLS, 1974). A era da globalização reflexiva ou planetária é marcada pela diminuição e mesmo pela falta de bem-estar social, trazendo novos riscos à sociedade, especialmente ao analisarmos três grandes áreas da vida social: condições de vida, relações sociais e cultura e comunicação (INGROSSO, 2007).

Num contexto de forte individualização, fragmentação e instabilidade, o moderno atual rejeita a permanência, fragmentando o tempo em episódios, erradica indivíduos, cancela biografias, erodindo qualquer certeza ao celebrar o risco (VERALDI, 2015). Independente do nome que se dê a esta realidade: pós-modernidade (HARVEY, 2014), modernidade líquida (BAUMAN, 2002), modernidade reflexiva (GIDDENS, LASH e BECK, 2012) ou sociedade do risco (BECK, 2011); observa-se uma efetivação da possibilidade de se jogar os modos da própria presença. $A$ estranheza e a indiferença no espaço urbano e especialmente metropolitano, garantem, de um lado a liberdade de humanizá-lo, porém o sentimento de solidão é extraordinariamente crescente (AUGUSTONI, 2015).

A ação política pode acentuar ou diminuir desigualdades, seja pelo processo de planejamento, por exemplo, modificando as possibilidades construtivas, seja implementando sistemas de bem-estar, como os diversos serviços públicos e infraestruturas (TACCHI, 2015). Desta forma, boas práticas de governança, mais democráticas e participativas, poderiam gerar uma cidade mais justa e inclusiva. $O$ território urbano atual é caracterizado por essa nova modernidade, onde espaço, tempo e individualidade marcam as relações sociais e a configuração social do espaço. A complexidade das informações que podem ser codificadas por meio do espaço

\footnotetext{
${ }^{1}$ Departamento de Ciências da Qualidade de Vida, Universidade de Bolonha, Itália.

2 Programas "Cidades Saudáveis" e "Planejamento Urbano Saudável"
} 


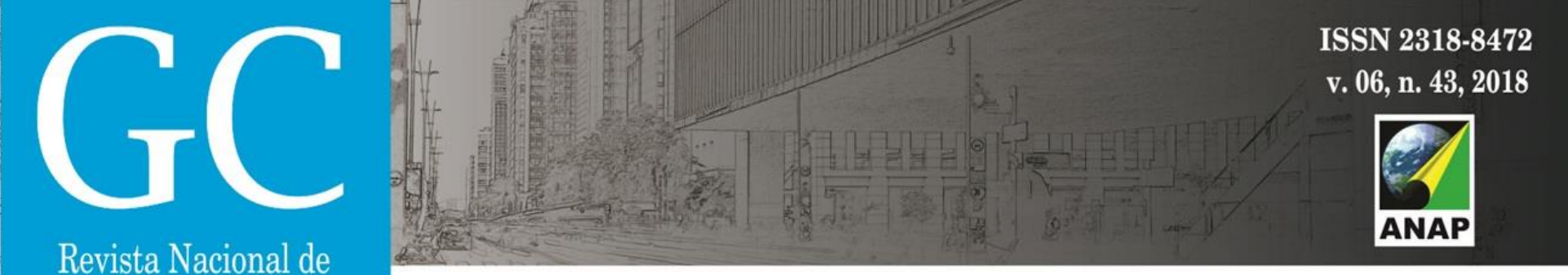

Gerenciamento de Cidades

urbano demostra a relevância do planejamento e controle social nas cidades contemporâneas. $\mathrm{O}$ espaço é vinculado às relações sociais, sendo construído e pensado à luz destas práticas. Na perspectiva contemporânea, o espaço alargado, graças à velocidade dos deslocamentos e mesmo da possibilidade virtual de deslocamento, tem acelerado a individualidade, uma vez que os indivíduos têm se proposto interpretar por si mesmo as informações que the chegam, tornando-se referência para uma nova visão do espaço (AGUSTONI e SANSEVIERO, 2015).

\section{RELAÇÃO ENTRE SAÚDE E PLANEJAMENTO URBANO}

A ligação entre saúde e planejamento urbano vem de longa data, pode-se dizer que o planejamento urbano nasceu também, ou exclusivamente, para tratar os problemas de saúde dos habitantes da nascente cidade moderna europeia (BELLAVITI, 2014). O paradigma higienista do planejamento visava o melhoramento das condições higiênico-sanitárias e habitacionais na cidade superpopulosa da primeira Revolução Industrial. Atualmente as grandes cidades europeias estão muito mudadas, graças ao planejamento e às políticas urbanas passaram de lugar de doenças e epidemias a lugares de promoção da saúde e melhores condições de vida, atrativas para se morar e para a vida social.

A relação do urbanismo e do planejamento urbano com tema da saúde pública e do bem-estar foi se tornando menos reconhecida e direta ao longo tempo. A perda deste reconhecimento deixou espaço a novas e insurgentes "questões urbanas", como a regulação da mobilidade, a organização urbana e valorização do solo, até a recente temática do aumento da competição urbana frente ao cenário global.

A Carta de Atenas, de 1933, surgiu materializando as propostas debatidas nos Congressos Internacionais de Arquitetura Moderna (CIAM), tentando propor medidas para o desenvolvimento urbano, promovendo uma aproximação das áreas da saúde e urbanas ao definir como eixos do planejamento a circulação, o trabalho, a moradia e a diversão (SPERANDIO, FRANCISCO FILHO e MATTOS, 2016).

Na fase mais recente do desenvolvimento urbano, ao mesmo a partir dos anos 1980, tem sido reproposta, de forma quase alarmante, a ligação entre saúde pública e os ambientes de vida, dando corpo a novas configurações do "mal-estar" e do "desconforto urbano". Ora ligado aos fenômenos contemporâneos de insalubridade, especialmente a poluição atmosférica e sonora, mas também aos novos processos de degradação territorial, de desconforto e exclusão habitacional, de crise do espaço público, de fragmentação social e empobrecimento, de crescimento da insegurança e do sofrimento psíquico (BELLAVITI, 2014).

Não por acaso a OMS reportou, já nos anos 1980, um novo modelo social da saúde (CARTA DE OTAWA, 1986), lançando o Movimento Cidades Saudáveis como estratégia integrada para promoção da saúde nos contextos urbanos e metropolitanos (WESTPHAL, 2000; DONISETTI, 2015). A redescoberta da ligação entre estado de saúde dos moradores das cidades e metrópoles com o planejamento urbano vem logo em seguida, com a aproximação do 


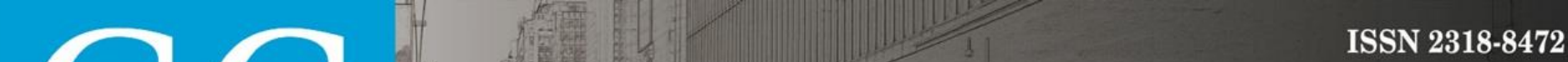

Revista Nacional de Gerenciamento de Cidades

"Healthy Urban Planning", ação estratégica formulada pela OMS no âmbito da estratégia saúde para todos e ligado ao projeto de Cidades Saudáveis (TSOUROU, 2015).

Se de fato a saúde, entendida como qualidade de vida, tem declinado nas cidades contemporâneas, as políticas de planejamento e gestão do território são identificadas como âmbito privilegiado de ação para a promoção da saúde. As principais questões que emergem no debate atual são: 1) quais interpretações da condição urbana contemporânea, temas, questões e demandas sociais, faz referimento a ideia de cidade saudável? 2) como essa ideia pode ser recusada operativamente e por meio de quais reformulações de abordagens e práticas de planejamento pode ser viabilizada?

O novo modelo social da saúde, ao considerar condicionantes socioeconômicos, culturais, ambientais, habitacionais, ocupacionais e das relações sociais, pode ser um ponto de partida para uma exploração e reconstrução das relações entre planejamento urbano e saúde (BELLAVITI, 2014). Ao considerar como determinantes da saúde as condições sociais em que as pessoas vivem e trabalham, introduz como elemento de intervenção as condições sociais que afetam a saúde e potencialmente podem ser alterados pelo planejamento urbano (BUSS, PELLEGRINI FILHO, 2007).

A fase anterior, modelo biologicista, focada na confiança na possibilidade de imunização dos indivíduos em relação aos patógenos presentes no ambiente, dominou o século $X X$ até o final dos anos 1980. Agora são encontradas muitas outras possibilidades de causas de doenças e mortes, devido a outros fatores, mais ligados ao contexto e estilo de vida. Sob esta base surge a estratégia "Cidades Saudáveis", visando deslocar as políticas locais de promoção da saúde para os lugares de vida das pessoas (BELLAVITI, 2014).

\section{SAÚDE COMO EXPRESSÃO DO BEM-ESTAR E QUALIDADE DE VIDA}

No campo da saúde podemos identificar alguns movimentos ideológicos que correspondem a crenças e pressupostos compartilhados por determinados grupos de sujeitos sociais, servindo como referencial para a ação: flexnerismo, medicina preventiva, saúde comunitária e saúde coletiva ou promoção da saúde (PAIM e ALMEIDA FILHO, 2000).

O Relatório Flexner foi publicado no início do século XX e redefiniu as bases do ensino e prática médica centralizados em fortes princípios tecnológicos, com separação das dimensões individual e coletiva, pública e privada, biológica e social, curativa e preventiva. A medicina preventiva surgiu da união das vertentes da higiene, da discussão dos altos custos da atenção médica e das responsabilidades médicas, caracterizando-se como movimento ideológico que mantinha o discurso da organicidade porém se abrindo para uma leitura mais liberal dos problemas de saúde. Já a proposta da saúde comunitária recuperou o discurso preventivista dando ênfase especial às ciências sociais aplicadas aos problemas de saúde. Porém um grande marco na mudança de paradigma foi a publicação do Relatório Lalonde no Canadá, em 1974, apresentando a ideia de que é necessário acrescentar vida aos anos e não apenas anos à vida. 


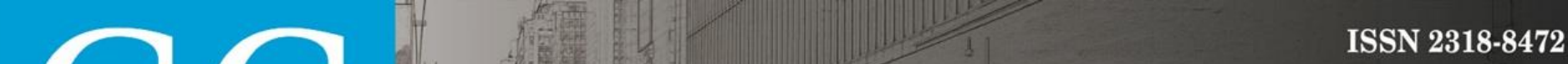

Revista Nacional de Gerenciamento de Cidades

A mudança do paradigma flexneriano, de enfoque biológico e bacteriológico, para o da produção social da saúde implica considerar que numa determinada sociedade, em seu tempo histórico, estando sujeita a regras definidas, existem capacidade de gerar fluxos de produção de fatos que vão acumulando ou desacumulando saúde.

A evolução da concepção de saúde levou a uma visão positiva da saúde, em oposição à visão negativa de que a saúde seria a ausência de doenças e enfermidades. Ao alterar o foco do indivíduo para a sociedade e do tratamento para a prevenção e promoção a saúde passa a ser considerada como um estado de completo, ainda que relativo, bem-estar físico, psíquico e social (SIMÕES, 2007). Ao lidar com esse sentido pleno, tão amplo como a própria noção de vida, considera-se que promover a saúde é promover a vida em suas múltiplas dimensões, envolvendo ações do âmbito global do Estado ao âmbito da singularidade e da autonomia dos sujeitos, responsabilidade esta que não pode ser atribuída a uma única e exclusiva área do conhecimento ou práticas específicas (CZERESNIA e FREITAS, 2009).

Embora as expressões Qualidade de Vida e Bem-Estar estejam sendo banalizadas na atualidade, ambos conceitos ponderam um conjunto mais ou menos amplo de variáveis, como: emprego, habitação, acesso à educação, à saúde, à cultura e às práticas do tempo livre. $\mathrm{O}$ acesso à qualidade de vida e bem-estar dependem do nível social, econômico e cultural das populações, estando mais relacionados às procuras que às ofertas destes serviços (GASPAR, 2007).

O conceito de qualidade de vida se tornou de uso comum na sociedade altamente industrializada após a crise da ideia de bem-estar social (TACCHI, 2007). Ele introduz uma valorização de horizontes desejáveis, guarda relação com a satisfação das necessidades humanas, bem como com a capacidade de uma comunidade desfrutar de uma vida média longa e saudável. Porém outros fatores são fundamentais, relativos à sociabilidade como suporte a uma percepção mais positiva da qualidade de vida (VITTE, 2009).

O problema da qualidade de vida surge e expande sobretudo com o advento da classe média, quase como uma forma de apreciar as vantagens de comodidades e serviços, mas também de poder ter experiências diretas e imediatas (CIPRIANI, 2014). A saúde e a qualidade de vida estão ligadas intimamente, pois esta é vista como o êxito de uma boa condição de saúde dos membros de uma comunidade, e ao mesmo tempo, a possibilidade de conduzir uma existência de qualidade, do ponto de vista da riqueza das relações sociais, da satisfação com o trabalho, de bons estilos de vida (NUVOLATI, 2014).

As necessidades humanas são regidas por valores relacionados ao bem-estar social e à diferença, os primeiros vinculam-se com o bem-estar individual em função da saúde, segurança e riqueza, já os segundos se referem a respeito, integridade, afeto e derivados das relações humanos. Ao qualificar a qualidade vida como urbana, considera-se que a cidade é o lugar da manifestação do individual e da experiência coletiva, numa multiplicidade de trocas que ajudam a produção da sociabilidade. A cidade é entendida como um espaço concebido, 


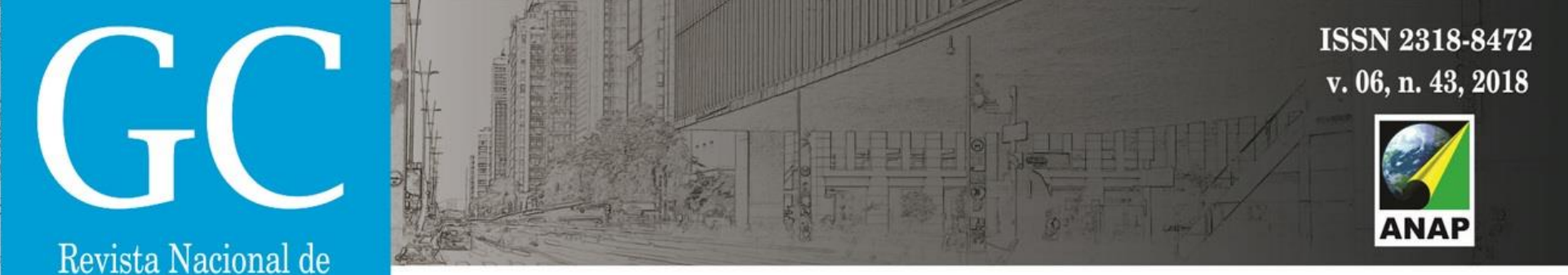

Gerenciamento de Cidades

vivido e percebido, agregando símbolos e valores elaborados por meio das impressões e experiências pessoais e coletivas (VITTE, 2009).

\section{MOVIMENTO CIDADES SAUDÁVEIS E PLANEJAMENTO URBANO SAUDÁVEL}

Falar em cidades saudáveis é falar em qualidade de vida urbana, mais que um conceito é uma estratégia com foco numa visão positiva da saúde como qualidade de vida, focada na promoção da saúde e planejamento urbano. Não podemos pensar numa cidade saudável sem considerar as condições mínimas de existência e acesso a bens e serviços econômicos e sociais (emprego e renda, educação básica e alimentação adequada), além do acesso a bons serviços de saúde e infraestrutura urbana (saneamento básico, habitação, transporte de qualidade etc) (GALLO e BESSA, 2018).

É um movimento global, organizado pela OMS, com relação íntima com os projetos de cidades sustentáveis da Comissão Europeia. A saúde se abre para fatores externos de outros setores, incorporando questões de qualidade de vida e saúde nos instrumentos de planejamento e gestão urbanos (SIMÕES, 2007). A escolha de operar por meio de uma rede de cidades, desde sua criação em 1986, procurou garantir a experimentação de uma mesma proposta em contextos socioeconômicos e culturais diversos, permitindo, ao mesmo tempo, que cada cidade aplicasse a modalidade operativa e de gestão mais adaptada a sua realidade (DONISETTI, 2015).

Devemos considerar a cidade como uma estrutura geográfica, uma unidade administrativa, lugar do viver e do trabalhar, onde diferentes sistemas interagem em busca de um equilíbrio entre relações e conflitos de poder. É neste espaço, onde objetivos econômicos, políticos e culturais entram em jogo, que devesse buscar uma motivação de governos e sociedade civil para a melhoria das condições de vida e saúde de seus cidadãos. Para tanto, exige-se um forte caráter participativo, de mobilização e democratização, com vistas às mudanças estruturais nas relações excludentes nos diferentes níveis de gestão, especialmente o local, conciliando interesses econômicos com o bem-estar social (WESTPHAL, 2000).

Para uma saúde entendida como bem-estar total do indivíduo num ambiente, habitável, seguro e hospitaleiro, depende também dos próprios cidadãos, com seus estilos de vida próprios, suas relações sociais e seu relacionamento com o contexto natural e construído (BELLAVITI, 2014). Torna-se evidente o papel ativo que cada cidadão pode e deve ter na construção da qualidade urbana, porém, deve-se prestar atenção especial aos processos de individualização e fragmentação da nova modernidade (GIDDENS, LASH e BECK, 2012; VERALDI, 2015).

Os municípios que buscam ser saudáveis precisam unir forças do executivo e legislativo na adoção de políticas públicas integradas que busquem solucionar, de forma intersetorial e integrada, os problemas diagnosticados. O objetivo é proporcionar um ambiente físico limpo e seguro, um ecossistema estável e sustentável, alto suporte social isento de exploração, alto 


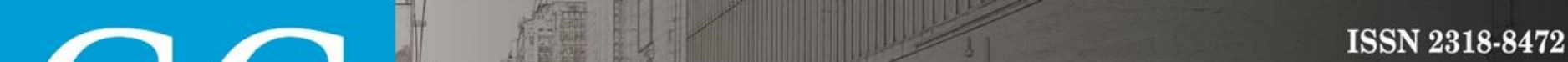

Revista Nacional de

grau de participação social, satisfação das necessidades básicas, acesso a experiências, recursos, contatos, interações e comunicações interpessoais, uma economia local diversificada e inovativa, orgulho pela herança biológica e cultura, além de serviços de saúde acessíveis a todos e um alto nível de saúde (ADRIANO et al, 2000).

A proposta "Healthy Urban Planning" ou Planejamento Urbano Saudável, pode ser vista como um aprofundamento da estratégia "Cidades Saudáveis", no campo das políticas públicas com implicação direta sobre as condições de vida na cidade (BELLAVITI, 2014).

Nasce durante o desenvolvimento da terceira fase do Projeto Cidades Saudáveis (1998-2002), refletindo os princípios da estratégia Saúde para Todos da OMS, em consonância com os princípios do desenvolvimento sustentável: equidade, participação social e cooperação intersetorial (TSOUROU, 2015).

No fundo, se delineia uma ideia de cidade mais habitável, que concede a todos seus diversos habitantes a possibilidade e liberdade de "estar bem" em seu próprio espaço de vida. Uma condição de estar bem que alude a um vasto complexo de bens e condições. Acesso a bens materiais como ter ou mudar de casa, ter um trabalho, viver num ambiente não degradado, poder utilizar jardins, parques e espaços públicos etc, mas também uma série de dimensões imateriais, como poder mudar o próprio projeto de vida, sentir-se seguro, não se sentir estigmatizado no lugar onde vive, contar com suporte de redes sociais, dentre outros.

O Planejamento Urbano Saudável é um campo de experimentação de políticas, projetos e práticas para requalificação e gestão urbana, conscientemente orientadas ao melhoramento das condições de salubridade e habitabilidade das cidades para todos seus habitantes, especialmente os mais vulneráveis. É colocar o bem-estar e a qualidade de vida como centro das políticas de planejamento urbano (BELLAVITI, 2014).

Um aspecto básico do princípio de equidade do planejamento urbano saudável, deveria incluir políticas com finalidade de melhorar a acessibilidade, uma vez que o espaço urbano é historicamente segregado, diminuindo distancias e aumento a segurança dos deslocamentos. Em relação ao princípio da participação da comunidade, trata-se de desenvolver e reforçar o sentido de comunidade, encorajando e empoderando as pessoas para que definam suas próprias necessidades, procurando soluções conscientes para as mesmas. No âmbito do planejamento urbano, o direito de participação devir do direito próprio de cada um de ser informado e consultado nos processos de decisão que determinam seus espaços de vida. Já a cooperação intersetorial diz respeito à necessidade de cooperação entre os diversos setores (edilícia, urbanismo, serviço social, serviços sanitários, ecologia, educação, transporte etc) como percurso para otimização na utilização de recursos e resultados, maximizando a sinergia e eficácia das intervenções. Tendo em mente que o bem-estar e a saúde dos cidadãos são valores de caráter holísticos (TSOUROU, 2015). 


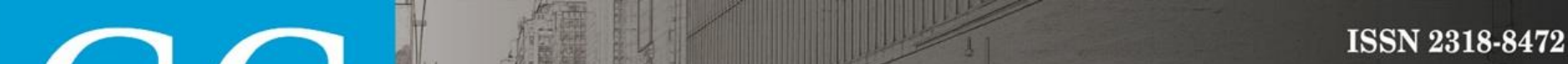

Revista Nacional de

\section{EXPERIÊNCIA ITALIANA NO PLANEJAMENTO URBANO SAUDÁVEL}

Foi desenvolvida na cidade de Milão uma perspectiva pragmática de um programa de pesquisa-intervenção, fruto da colaboração entre alguns setores administrativos da cidade (Direção de Planejamento Urbano e Direção de Serviços Sócio-sanitários, no âmbito do Projeto Cidades Saudáveis) e o Departamento de Arquitetura e Planejamento Urbano da Universidade Politecnico di Milano (BELLAVITI, 2015). O programa segui duas linhas de ação:

1) Interna à administração municipal (institucional), mediante a colaboração entre os responsáveis por políticas setoriais com finalidade de criar condições e possibilidades de constituir projetos integrados, partindo da evidência de que a realização de políticas urbanísticas inspiradas pelo Planejamento Urbano Saudável necessita de abordagens transversais aos tradicionais setores de intervenção: urbanismo, políticas sociais e de serviços, políticas para o meio ambiente, para o trabalho, educação etc. A ideia era envolver os atores institucionais com responsabilidades políticas e setoriais nos diversos setores pertinentes, procurando colocar em ação concretamente essa abordagem.

2) Junto à sociedade local (territorial), onde se pretendia pesquisar práticas de transformação do território, que apresentassem características de inovação em relação aos sujeitos que as conduziam (associações, terceiro setor, empresas privadas etc) e em relação às modalidades de desenvolvimento. Partiu-se da consideração de que as instituições públicas não podem cobrir todo o campo de ação das políticas urbanas e de outro lado, que as mesmas podem desenvolver uma atividade de facilitação, sustento e colaboração com a mobilização de energia proveniente da sociedade local.

Segundo Bellaviti (2015), as duas linhas de ação deveriam desenvolver-se paralelamente, na tentativa de dar voz e abrir um diálogo entre as dimensões institucional e territorial no interior da cidade, onde se movem, se entrelaçam, se acompanham, mas também, e normalmente, entram em conflito em relação à capacidade de construir um bom projeto público.

O primeiro passo para o desenvolvimento da experiência foi o reconhecimento das boas práticas institucionais e territoriais, considerando que o objetivo não era elaborar novos projetos, mas experimentar uma metodologia de trabalho intersetorial para a montagem de projetos integrais. Como segundo passo foi realizada uma experimentação de abordagem intersetorial e participativa de alguns projetos pilotos.

A metodologia de intervenção foi a colaboração (elaboração conjunta) entre os responsáveis setoriais dos projetos públicos da área selecionada e alguns sujeitos não institucionais ativos na mesma área. Foram definidos como experiências piloto: Bairro de Moradia Popular MoliseCalvairate, Área de Cascina Merlata-Via Barzaghi (uma grande área circundante ao Cemitério Maggiore, destinada a um parque), Área de Chiaravalle-Nosedo ex Porto di mare.

O maior desafio no processo foi a interação entre os funcionários municipais e os sujeitos locais, e também entre estes últimos e os pesquisadores, devido às diferentes racionalidades e 


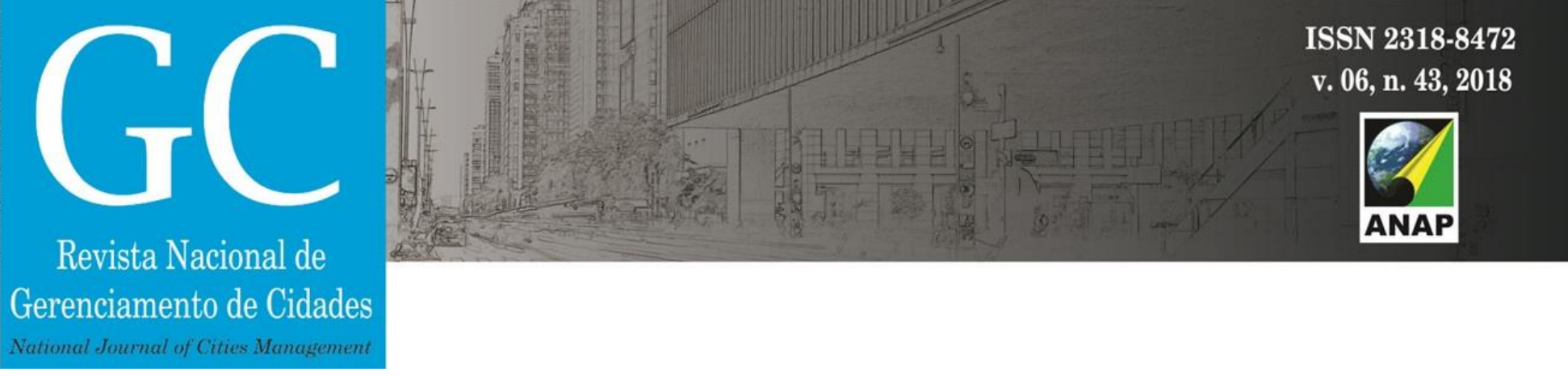

Figura 3: Área de intervenção de Chiaravalle-Nosedo ex Porto di mare, Milão, Itália

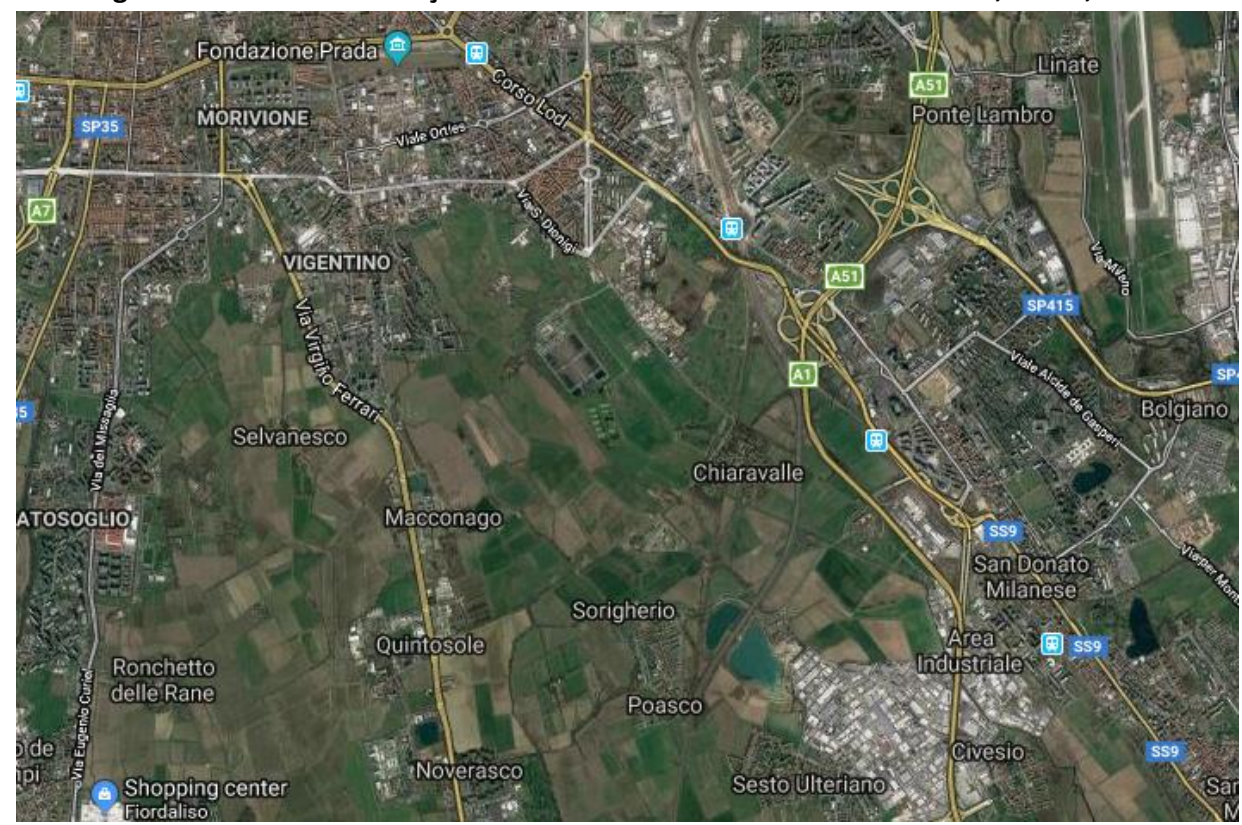

Fonte: Google Earth, 2018

\section{CONSIDERAÇÕES FINAIS}

Quando pensamos numa cidade saudável é impossível não associar o planejamento urbano e as políticas públicas de forma integrada e intersetorial, uma vez que é por meio destes que os objetivos de promoção da vida e da saúde no contexto urbano poderão ser alcançados. 0 Projeto Cidades Saudáveis surgiu há três décadas, como proposição da OMS para a promoção da saúde e reorientação de práticas e conceitos, tendo a cidades como lugar privilegiado, por ser onde as pessoas vivem, trabalham e se relacionam, agregando ou desagregando qualidade às suas vidas.

A mesma OMS, dando continuidade e visando operacionalizar e colocar em prática a estratégia das cidades saudáveis criou o Planejamento Urbano Saudável, proposta de cooperação intersetorial e integrada, abordando as dimensões ambiental, edilícia-urbanística-territorial e sócio-sanitária. A cidade de Milão/Itália construiu um projeto piloto nos moldes do programa, unindo diversos setores da administração, a universidade e pesquisa e agentes locais. Foram mapeadas iniciativas e projetos que abarcassem diversos setores e que poderiam ser integrados no conceito da proposta de intervenção e que estivessem relacionados com problemas e intervenções mais amplas.

No projeto piloto foram privilegiadas ações de recuperação de áreas abandonas e degradadas, com requalificação de áreas verdes e recuperação edilícia de bairros, buscando enfrentar o sofrimento social e psicológico das populações locais. Mesmo com as dificuldades de comunicação e integração entre os diferentes agentes sociais e de compatibilização de 
interesses e projetos, o diálogo e a mudança de perspectiva fizeram da experiência um importante passo rumo a construção de espaços mais habitáveis, saudáveis e humanizados na cidade contemporânea.

A mudança estrutural na forma de trabalhar e de pensar o planejamento é a principal inovação e revolução do Planejamento Urbano Saudável. As dificuldades são inerentes a uma forma inovadora de pensar, que altera processos de trabalho muitas vezes consolidados e cristalizados pelas burocracias e statos quo. Mas com a união de diversos setores, especialmente o público, a academia e a sociedade civil organizada é possível mudar a forma de planejar e gerir a cidade, rumo à criação de cidades mais saudáveis e participativas.

\section{AGRADECIMENTO}

Agradecemos à Coordenação de Aperfeiçoamento de Pessoal de Nível Superior - CAPES, Ministério da Educação - MEC, pela concessão de bolsa pelo Programa Institucional de Bolsas de Doutorado Sanduíche no Exterior/Processo no 88881.189238/2018-01.

\section{REFERÊNCIAS BIBLIOGRÁFICAS}

ADRIANO, Jaime Rabelo; et al. A construção de cidades saudáveis: uma estratégia viável para a melhoria da qualidade de vida? Ciência \& Saúde Coletiva, 5(1): 53-62, 2000.

AUGUSTONI, Alfredo. Teoria sociologica e immagini della città. In: AGUSTONI, Alfredo; GIUNTARELLI, Paolo; VERALDI, Roberto. Sociologia dello spazio, dell'ambiente e del territorio. Milano: FrancoAngeli, 2015.

AGUSTONI, Alfredo; SANSEVIERO, Serena. Tempo, spazi, distanze e luoghi. In: AGUSTONI, Alfredo; GIUNTARELLI, Paolo; VERALDI, Roberto. Sociologia dello spazio, dell'ambiente e del territorio. Milano: FrancoAngeli, 2015.

BAUMAN, Zygmunt. Modernità liquida. Roma: GLF editora Laterza, 2002.

BAUMAN, Zygmunt. Medo líquido. Rio de Janeiro: Zahar, 2008.

BECK, Ulrich. Sociedade de risco: rumo a uma outra modernidade. São Paulo: Editora 34, 2011.

BELLAVITI, Paola. La città, la salute e la pianificazione urbana. In: NUVOLATI, Giampaolo; BORDOGNA, Mara Tognetti. Salute, ambiente e qualità della vita nel contesto urbano. Milano: FrancoAngeli, 2014.

BELLAVITI, Paola. Una città in salute - Healthy Urban Planning a Milano: un approccio e un programma per una città più sana, vivibile, ospitale. Milano: FrancoAngeli, 2015.

BUSS, Paulo Marchiori; PELLEGRINI FILHO, Alberto. A saúde e seus determinantes sociais. PHYSIS: Rev. Saúde Coletiva, 17(1): 77-93, 2007.

CARTA DE OTAWA. Primeira Conferência Internacional sobre Promoção da Saúde, 1986. In: BRASIL, Ministério da Saúde. As cartas da Promoção da saúde. Brasília: Ministério da Saúde, 2002.

CASTELLS, Manuel. La questione urbana. Venezia: Marsilio, 1974. 
CIPRIANI, Roberto. Alle origini della salute urbana. In: NUVOLATI, Giampaolo; BORDOGNA, Mara Tognetti. Salute, ambiente e qualità della vita nel contesto urbano. Milano: FrancoAngeli, 2014.

CZERESNIA, Dina; FREITAS, Carlos Machado de. Promoção da saúde: conceitos, reflexões, tendências. Rio de Janeiro: Editora Fiocruz, 2009.

DONISETTI, Laura. II progetto Città Sane. In: BELLAVITI, Paola. Una città in salute: Healthy Urban Planning a Milano un approccio e un programma per una città più sana, vivivile, ospitale. Milano: FrancoAngeli, 2015.

GALLO, Douglas; BESSA, Eliane Ribeiro de Almeida da Silva. Saúde e espaço urbano: a promoção de cidades mais saudáveis e sustentáveis. Rev. Nac. de Gerenciamento de Cidades, 6 (38): 29-43, 2018.

GASPAR, Jorge. Cidade, saúde e urbanização: apontamentos e notas de leitura. In: SANTANA, Paula. A cidade e a Saúde. Coimbra: Gráfica de Coimbra, 2007.

GIDDENS, Anthony; LASH, Scott; BECK, Ulrich. Modernização reflexiva: política, tradição e estética na ordem social moderna. São Paulo: Editora Unesp, 2012.

HARVEY, David. Condição pós-moderna. São Paulo: Loyola, 2014.

INGROSSO, Marco. Senza benessere sociale: nuovi rischi e attese di qualità della vita nell'era planetaria. Milano: FrancoAngeli, 2007.

LEFEBVRE, Henri. A revolução urbana. Belo Horizonte: Editora UFMG, 1999.

LEFEBVRE, Henri. O direito à cidade. São Paulo: Centauro, 2001.

NUVOLATI, Giampaolo. Qualità della vita urbana e salute: prospettive di analisi sociologica. In: NUVOLATI, Giampaolo; BORDOGNA, Mara Tognetti. Salute, ambiente e qualità della vita nel contesto urbano. Milano: FrancoAngeli, 2014.

PAIM, Jairnilson Silva; ALMEIDA FILHO, Naomar de. A crise da saúde pública e a utopia da saúde coletiva. Salvador: Casa da Qualidade Editora, 2000.

SIMÕES, José Manuel. Construindo cidade saudável. In: SANTANA, Paula. A cidade e a Saúde. Coimbra: gráfica de Coimbra, 2007.

SPERANDIO, Ana Maria Girotti; FRANCISCO FILHO, Lauro Luiz; MATTOS, Thiago Pedrosa. Política de promoção da saúde e planejamento urbano: articulações para o desenvolvimento da cidade saudável. Ciência \& Saúde Coletiva, 21(6): 1931-1937, 2016.

TACCHI, Enrico Maria. Immagine dele transizione urbane: appartenenze sociali e definizioni della qualità della vita. Milano: FrancoAngeli, 2007.

TACCHI, Enrico Maria. Luoghi, paesaggi e agire sociale: alcune considerazioni introduttive. In: AGUSTONI, Alfredo; GIUNTARELLI, Paolo; VERALDI, Roberto. Sociologia dello spazio, dell'ambiente e del territorio. Milano: FrancoAngeli, 2015.

TSOUROU, Catherine. L'Healthy Urban Planning: pianificare la città sana. In: BELLAVITI, Paola. Una città in salute: Healthy Urban Planning a Milano - un approccio e un programma per una città più sana, vivivile, ospitale. Milano: FrancoAngeli, 2015. 


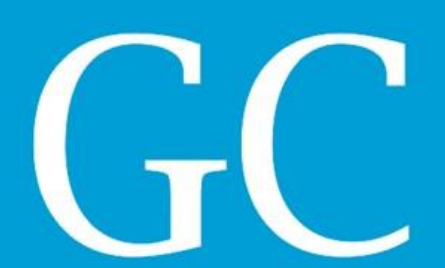

Revista Nacional de

ISSN 2318-8472

v. 06, n. 43,2018

Gerenciamento de Cidades

National Journal of Cities Management

VERALDI, Roberto. Tra marginalità e sviluppo urbano: alcune questioni preliminarei. In: AGUSTONI, Alfredo; GIUNTARELLI, Paolo; VERALDI, Roberto. Sociologia dello spazio, dell'ambiente e del territorio. Milano: FrancoAngeli, 2015.

VITTE, Claudete de Castro Silva. A qualidade de vida urbana e sua dimensão subjetiva: uma contribuição ao debate sobre políticas públicas e a cidade. In: VITTE, Claudete de Castro Silva; KEINERT, Tânia Margarete Mezzomo.

Qualidade de vida, planejamento e gestão urbana: discussões teórico-metodológicas. Rio de Janeiro: Bertrand Brasil, 2009.

WESTPHAL, Marcia Faria. O movimento cidade/municípios saudáveis: um compromisso com a qualidade de vida. Ciência \& Saúde Coletiva, 5(1): 39-51, 2000. 